\title{
CYCLIC STRESS ANALYSIS OF POLYESTER, ARAMID, POLYETHYLENE AND LIQUID CRYSTAL POLYMER YARNS
}

\author{
Felipe Vannucchi de Camargo ${ }^{a, *}$, Carlos Eduardo Marcos Gullherme $^{a}$, \\ Cristiano Fragassa ${ }^{b}$, Ana Pavlovic ${ }^{b}$ \\ a Policab - Escola de Engenharia, Universidade Federal do Rio Grande, Av. Italia km 08 Campus Carreiros, \\ 96203-900 Rio Grande/RS, Brazil \\ ${ }^{b}$ DIN - Department of Industrial Engineering, Alma Mater Studiorum University of Bologna, viale \\ Risorgimento 2, 40136 Bologna, Italy \\ * corresponding author: fevannucchi@gmail.com
}

\begin{abstract}
Mooring ropes used in offshore oil platforms are exposed to a set of extreme environmental conditions that can be crucial to their behaviour in service. Considering the elevated mechanical demands on these ropes imposed by both the undersea environment and the station keeping of the vessel, this paper is focused on the experimental determination of the yarns fatigue behavior. In order to be able to foresee and compare their general wear rate, a diagram that correlates the force to which the specimens are submitted to the number of cycles for failure for each material is achieved. The analyzed fibers are Polyester, Aramid, Polyethylene and Liquid Crystal Polymer (henceforth quoted as PET, AR, PE and LCP, respectively), and this work followed a pattern composed by a fixed test frequency and an established maximum stress for the diagrams.
\end{abstract}

KEYWORDS: fatigue; polymer; synthetic fiber; offshore oil platform; ultra-deep water.

\section{INTRODUCTION}

The findings of oceanic oil basins, specifically the ones in ultra-deep water regions (with depths over 2000 meters), have been both exciting news for the oil industry and a challenge for engineers worldwide, entrusted with the endeavour to make the oil extraction a feasible task. Previous technological boundaries had to be pushed, including the ones related to mooring systems, once the ambiance underseas with an intense pressure gradient along with environmental influences is particularly severe for its components and plants.

Simultaneously, the industrial usage of polymers has grown for decades due to their light weight and good mechanical properties, which can be exemplified by the usage of polymers such as Polyethylene as matrix for wooden reinforced composites, providing an enhanced creep resistance to the material [1], Aramid used for structural components in racing cars [2, and Polyvinylidene Difluoride (PVDF) reinforced composites for high-speed woodworking machines parts [3].

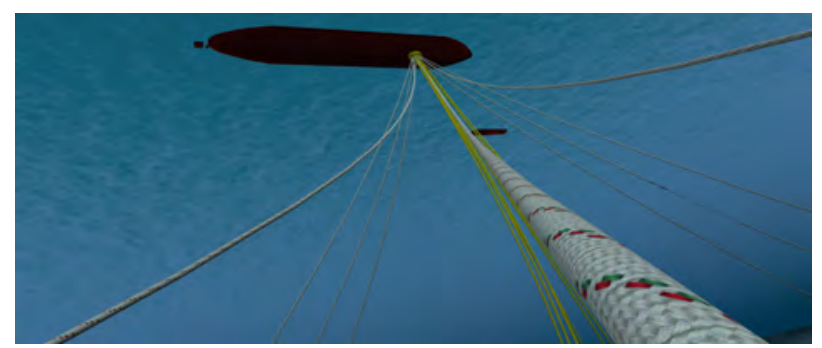

Figure 1. Pivoted mooring system with synthetic ropes used on a FPSO oil platform.
This growing trend strengthened the concept of using synthetic ropes to moor oil platforms, once long steel cable lines would bring along factors such as high maintenance fees and high weight. Figure 1 shows a synthetic mooring line used on a FPSO platform through a pivoted turret anchoring layout.

This work is focused on the case of the semisubmersible platforms: along with the material substitution, a change in the mooring configuration itself was implemented replacing the catenary system by the taut-leg. In the first one, the end of the line is entirely laid on the seabed, causing exclusively horizontal stress on it. However, in the taut-leg mode, the mooring line is always axially tensioned; exposing the importance of having a proper knowledge regarding the mechanical behaviour of polymeric materials experimentally, which is encouraged by the literature [4. An illustration of the aforementioned mooring configurations is shown in Figure 2

With the advent and large-scale usage of the tautleg mooring system over the catenary system, the

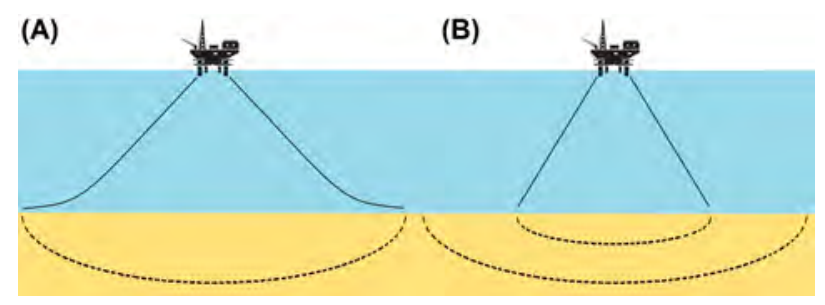

Figure 2. Comparison between the mooring radii of two layouts: catenary (A) and taut-leg (B). 


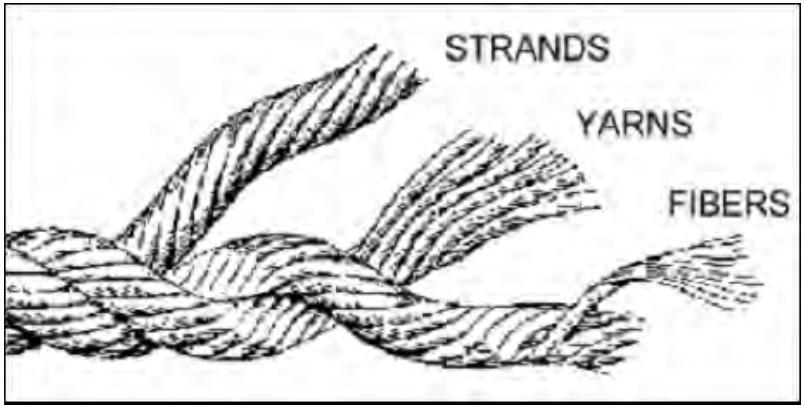

Figure 3. The yarn scale when compared to superior aggregations.

ropes are constantly under tension: either for or against the wind, intermittent forces (i.e., waves) and stream influences - characterizing a fatigue condition. Therefore, the aim of this paper is to provide an experimental-based prediction for the resistance of the main commercial synthetic fibres used for this application nowadays, by analyzing their endurance under certain cyclic loads.

Seeking to predict the mechanical behaviour of the most commonly used synthetic fibres within this specific application, researches have been carried out to evaluate wear mechanisms such as creep at low temperatures [5] and stiffness [6] of these yarns. Thus, aiming to enhance the technical analysis on this paper, other tests besides fatigue were conducted, including creep, tensile and linear density (which allowed the determination of the linear tenacity).

\section{MAterial AND Methods}

\subsection{Fatigue}

Components of a mechanical system may be exposed to inherent cyclical efforts of its function, being subjected to a structural fatigue wear. Unlike metal, where fatigue is identified by a crack propagation, this phenomenon has different characteristics when it comes to polymeric materials.

In this case, the sensitivity to wear is greatly increased by factors such as mode, rate, and amplitude of loading; frequency, temperature, relative humidity [7, and environmental pH [8, 9]. Actually, on real operation conditions, the sea-water represents a considerable degradation factor to the synthetic fibres properties 10 .

Within this application, fatigue is characterized as the main degradation mechanism of the synthetic fibres [4, rather than factors such as surface wear, tensile and structural imperfections and environmental factors that can be corrected with a carefully planned rope design. The fatigue effect over these fibres can be further subdivided in two subsequent steps of resistance decrease 4]: hysteresis heating and axial compression [11.

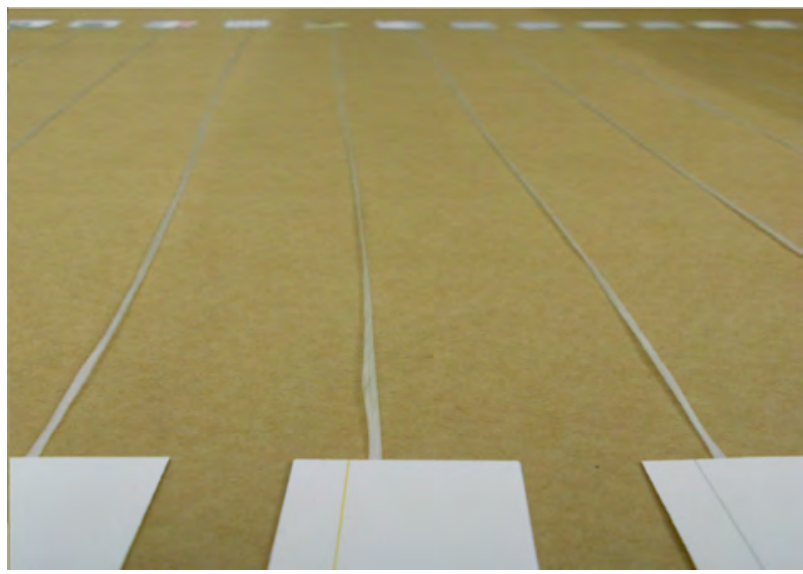

Figure 4. Specimen samples with socketed end in detail.

\subsection{Feasibility of the Experimental PHASE}

Polyester ropes are known to have a resistance to fatigue equal to or more effective than steel cables [4]. The life of a Polyester cable subjected to a continuous cycling between $70 \%$ and $0 \%$ MBL (Maximum Breaking Load) is approximately 100000 cycles. When the peak load is decreased to $60 \% \mathrm{MBL}$, the endurance rises to 1 million cycles 4 .

Therefore, chronological and economic feasibility is a concern for this work, since accelerating the test through frequencies higher than the operation's would produce results unfaithful to reality [7].

\subsection{Testing Parameters}

The establishment of a test script suitable to polymeric materials was necessary, since the literature fails to present it for non-metallic materials [7].

The standard specimen scale is the Yarn, due to the availability of technical references such as standards and papers. The mooring ropes used for offshore station keeping are a group of twisted sub cables which are composed by twisted strands. A further visual description of the yarn scale compared to a strand is shown in Figure 3

The specimens (see Figure 4) were $500 \mathrm{~mm}$ long, untwisted (with their fibres on a parallel configuration) with cardboard sandwich resin socketed ends [12] (because of it's superior performance over other alternatives [4]).

The testing machines used in this work are:

- OHAUS Adventurer AR2140: electronic precision scale with the resolution of $1 x 10 g^{-4}$ used for the linear density tests.

- INSTRON 3365: pneumatic, used for the tensile and creep tests, with a pneumatic clamp.

- INSTRON 8801: servo-hydraulic, used for the fatigue tests, with a mechanical screw-tightening clamp. 


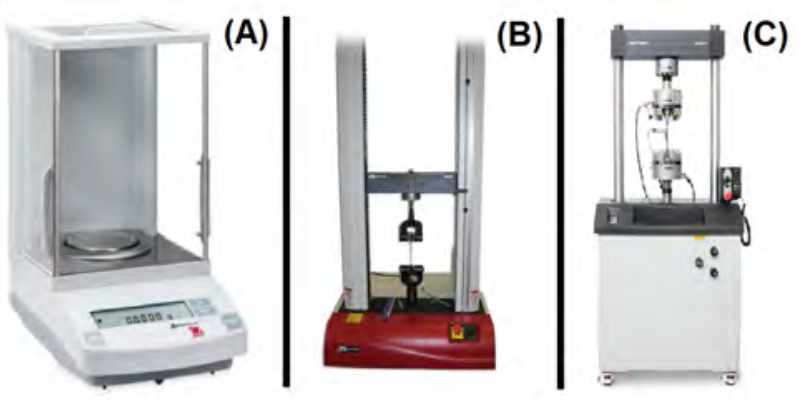

Figure 5. Commercial pictures of the three testing machines used for this work: OHAUS scale (A), Instron 3365 (B) and Instron 8801 (C).

Commercial pictures of the three machines are displayed in Figure 5

For all experiments, specimens were obtained extracting samples of yarn directly from the manufacturer's coil using a manual reference tension without direct hand contact with the material [13 15]. After that, the specimens remained by the indicated time in standard atmosphere [16] of $20 \pm 2{ }^{\circ} \mathrm{C}$ and $65 \pm 4 \% \mathrm{RH}$ until the time of testing, in which the air flow was controlled to avoid the Gough-Joule effect [13].

In order to determine the main mechanical characteristics of the yarns of each material, preliminary tests of linear density, tension and creep were conducted.

Linear density (LD) specimens, differently from all the other, were one meter long and had no socketed ends. Ten specimens per material were weighted on the scale during a stabilization time of 5 minutes per test.

Tensile tests were performed with a pre-load of 1 Newton. The loading rate was imposed as a percentage of the specimen length: $50 \%$ for AR $(250 \mathrm{~mm} / \mathrm{min})$ and $100 \%$ for other materials $(500 \mathrm{~mm} / \mathrm{min})$ [13, providing a proper loading rate in order to avoid the wear effect caused by impact. Thirty specimens of each material were tested.

The creep tests started with a pre load of 1 Newton, followed by a static load ramp of $250 \mathrm{~N} / \mathrm{min}$, and a force-based hold at $80 \%$ or $90 \%$ of the average Yarn Breaking Load (YBL) determined by the tensile tests. For each of the two creep loads, 3 specimens were tested for all materials, i.e., 24 tests were carried out.

The pre-load applied before the tensile, creep and fatigue tests is a standardized parameter [13] important to soften any impact-related wear. In other polymeric materials such as composites, for example, it is proofed that the application of a pre-load decreases the wear caused by impact [17].

Once provided with the results of these preliminary tests, linear tenacity (LT), expressed in [N/tex], can be calculated as a function of those results through

\begin{tabular}{ccc}
\hline Trough Load & Mean Load & Amplitude \\
\hline 10 & 50 & 40 \\
\hline 20 & 55 & 35 \\
\hline 30 & 60 & 30 \\
\hline 40 & 65 & 25 \\
\hline 50 & 70 & 20 \\
\hline 60 & 75 & 15 \\
\hline 70 & 80 & 10 \\
\hline 80 & 85 & 5 \\
\hline
\end{tabular}

TABLE 1. Loading ranges analyzed, in \% YBL.

the following equation:

$$
\mathrm{LT} \frac{[\mathrm{N}]}{[\operatorname{tex}]}=\frac{\mathrm{YBL}[\mathrm{N}]}{\mathrm{LD}[\operatorname{tex}]}
$$

Regarding fatigue, as quoted above, an experimental loading simulation totally faithful to the conditions of a mooring rope operation is impractical and possibly inconclusive due to the small sample that would be able to be tested. To backup this premise, one can quote the loading condition ranging from $50 \%$ to $40 \%$ YBL, in which a Polyester rope would take thousands of years to reach a fracture according to numerical simulations [4].

Nowadays, mooring ropes are designed to withstand utmost loadings, once on a severe storm condition the rope might cycle with an amplitude of $15 \% \mathrm{MBL}$ and a mean stress of $30 \%$ MBL. It is also known that even though fatigue is the main wear mechanism of those ropes, severe storms are considerably rare and do not represent a major concern. Instead, the leading wear factor is the cycling at small amplitudes and frequencies that goes on uninterruptedly over the 20 years of operation of a rope 4. Accordingly, it is clear that fatigue wear rates should be better understood in order to provide an optimal rope design, backing up the importance of introducing an experimental fatigue study [4].

Therefore, a frequency used in certification tests of $0.1 \mathrm{~Hz}$ [18] was adopted for this work along with loads simulating extreme conditions in pursuance of obtaining tangible experimental data: keeping the peak load at $90 \%$ YBL as a fixed parameter, 8 loading ranges were studied through the variation of the trough load from 10 to $80 \%$ YBL with a $10 \%$ YBL gradual increase, as Table 1 indicates.

The fatigue test is force-controlled (CRL - Constant Rate of Loading), and consists of a pre tension of 1 Newton [13, followed by a ramp with a controlled rate 13] which rises until the force corresponds to the first quadrant of the sinusoidal cycling to which the material is subjected, as shown in Figure 6 The sinusoidal wave shape was chosen because of its smoother loading-unloading transition when compared to other 


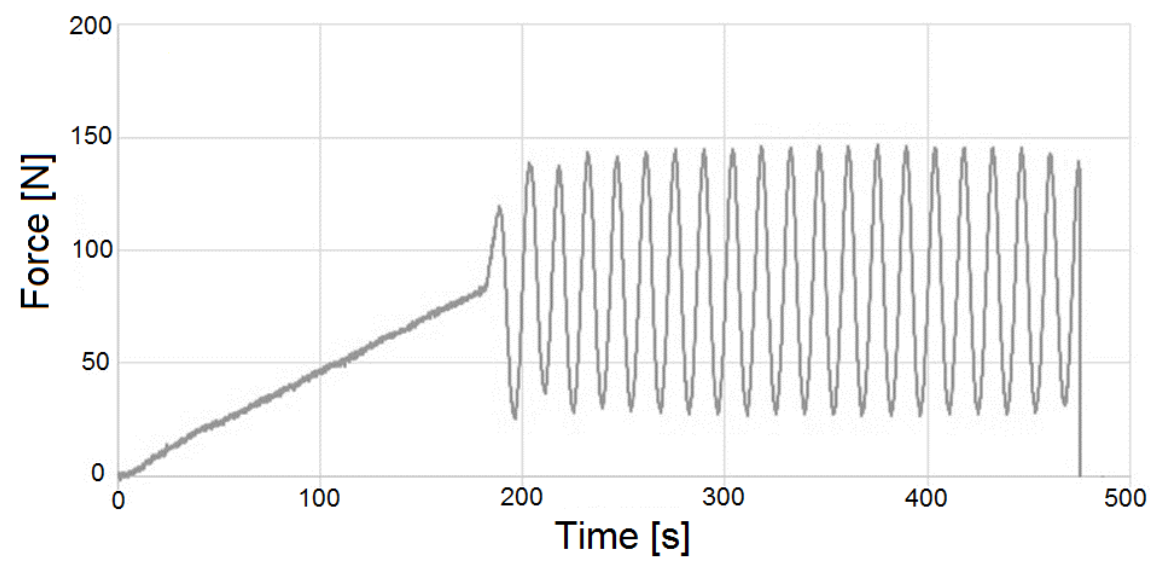

Figure 6. Illustration of the fatigue test.

\begin{tabular}{lccccc}
\hline Material & LD $[$ tex] & YBL $[\mathrm{N}]$ & LT $[\mathrm{N} /$ tex] & CR at 90 \% YBL $[\mathrm{h}]$ & CR at 80 \% YBL $[\mathrm{h}]$ \\
\hline PET & 225.64 & 165.441 & 0.733 & 0.32 & 35.886 \\
\hline AR & 358.68 & 641.250 & 1.788 & 0.479 & 31.028 \\
\hline PE & 170.69 & 552.175 & 3.235 & 0.0178 & 2.113 \\
\hline LCP & 170.70 & 359.911 & 2.108 & 0.036 & 2.814 \\
\hline
\end{tabular}

TABLE 2. Results of preliminary tests.

wave shapes such as triangular, saw-tooth and squared, which would cause an enhanced impact-related wear.

In total, 96 specimens were submitted to fatigue tests, being 24 specimens per material and 3 per load range considered.

\section{Results And Discussion}

The preliminary tests results are shown in Table 2 Finally, to define the behavior of the materials when subjected to sheer fatigue, curves were built relating the logarithm of the number of cycles to rupture $(\log N)$ with the trough force of the cyclic loading, expressed in \% YBL.

The highlighted points represent the average number of cycles for each load range, and the trend curves were selected according to the best correlation coefficient $\left(R^{2}\right)$ possible (even though the fitting functions may be distinct among the fibres), in order to assess statistical significance to Figures 7,10 .

Figure 11 displays the fatigue curves of the four materials studied altogether. Also, Table 3 shows the average number of cycles to rupture for each material and each load range.

\subsection{Preliminary tests}

On the one hand, the tensile tests revealed that the bigger the YBL is, the more fatigue resistant the material is. After all, the direct relation between the tests is evidenced once the materials resistance order (AR, PE, LCP, PET, decreasingly) is kept the same in both experiments.
On the other hand, linear tenacity results clarified that the strength-to-weight ratio is not determinant to predict the fatigue resistance, because they do not show a mutual proportional relation whatsoever.

The creep resistance does not have a proportional relation with the yarn breaking load as well. After all, even though PET and AR present the lowest and the highest yarn breaking loads, respectively, both materials have the highest resistance to creep among the four analyzed materials, with wide superiority over the others.

\subsection{FAtigue}

The exponential and polynomial demeanours of PET and LCP, respectively, have the same tendency: their fatigue resistance decreases as the loading amplitude decreases.

With the most significant average fatigue resistance, AR presents an optimal loading amplitude for endurance of approximately $15 \%$ to $20 \%$ YBL. Its average resistance draws attention, being far superior to the others, it is about fifteen times higher than the second highest average (see Table 3).

Similarly to AR, PE demonstrates an optimal loading amplitude of about $20 \% \mathrm{YBL}$, at the respective loading 90\%-50\%YBL. Nevertheless, both fibres present smaller resistances to fatigue at high and low loading amplitudes (of 40\% YBL and 5\% YBL) backed up by a polynomial tendency.

\section{Conclusions}

The presented work showed that it is attainable to realize an experimental study on fatigue of synthetic 


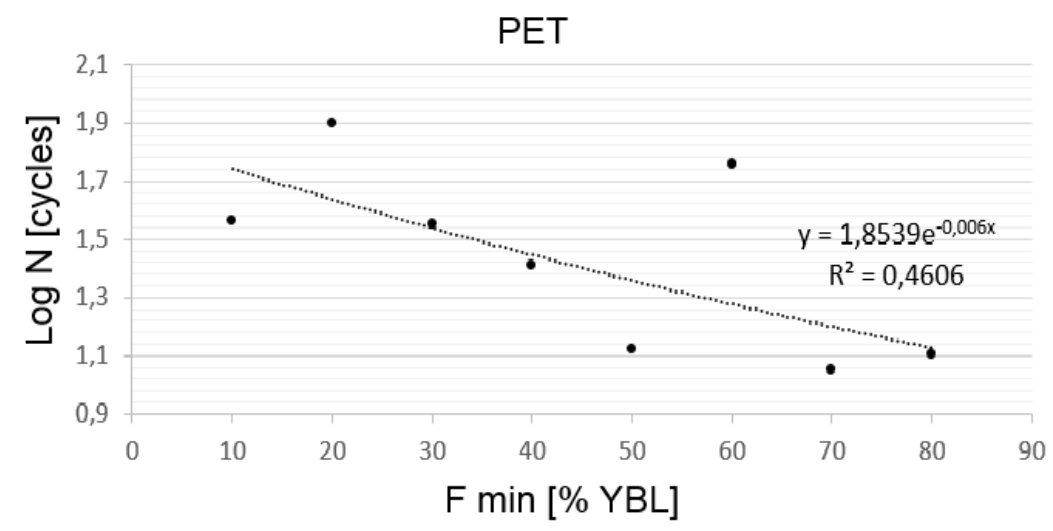

Figure 7. Fatigue trend of Polyester.

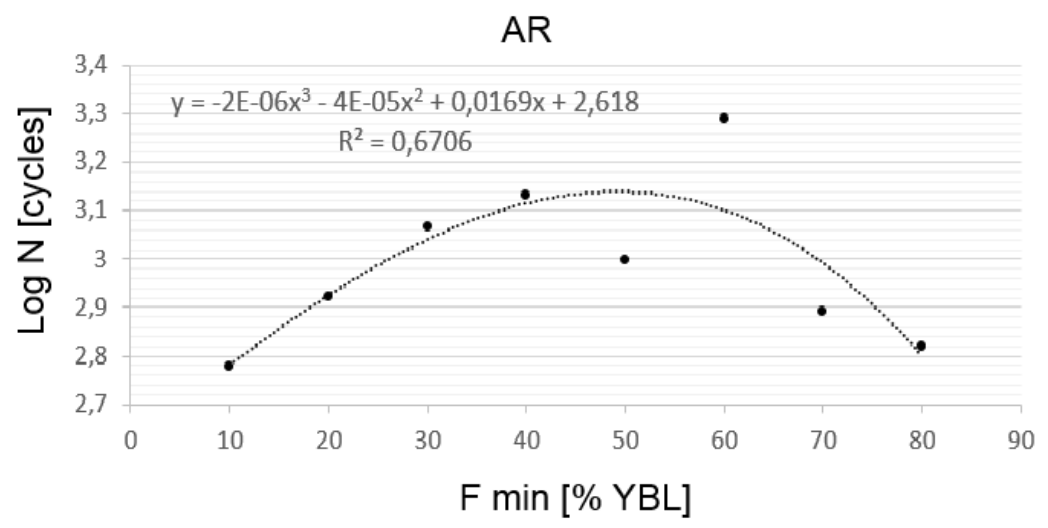

Figure 8. Fatigue trend of Aramid.

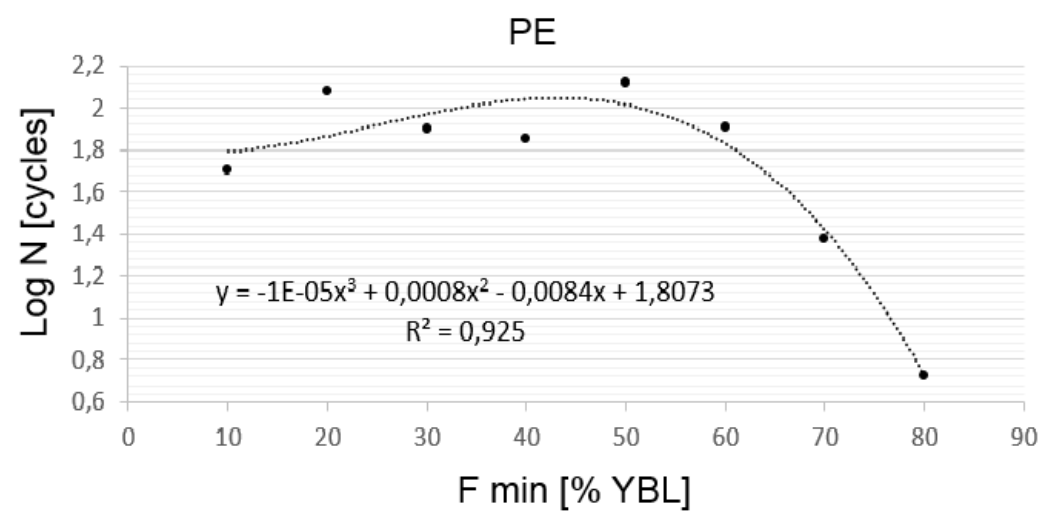

Figure 9. Fatigue trend of Polyethylene.

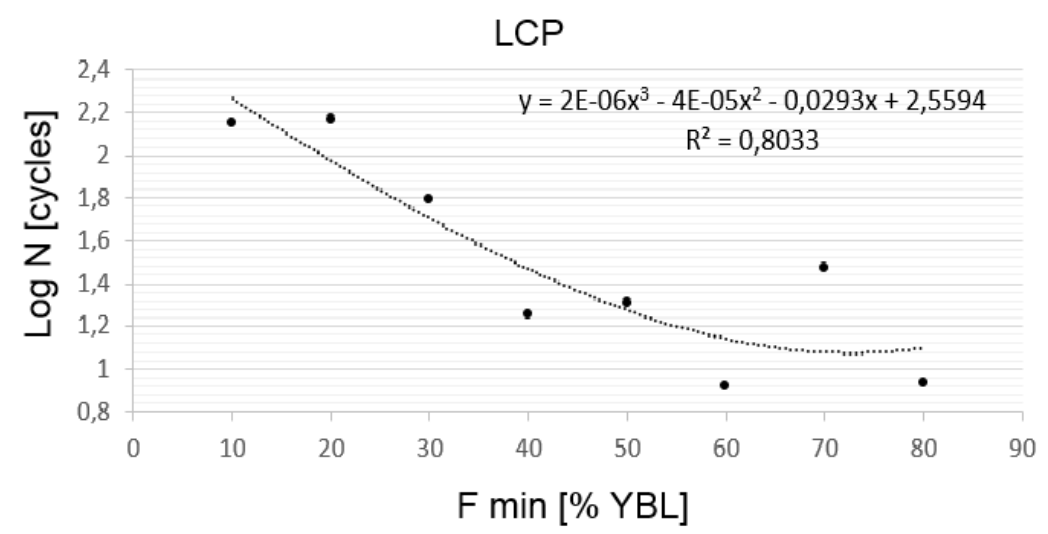

Figure 10. Fatigue trend of Liquid Crystal Polymer. 


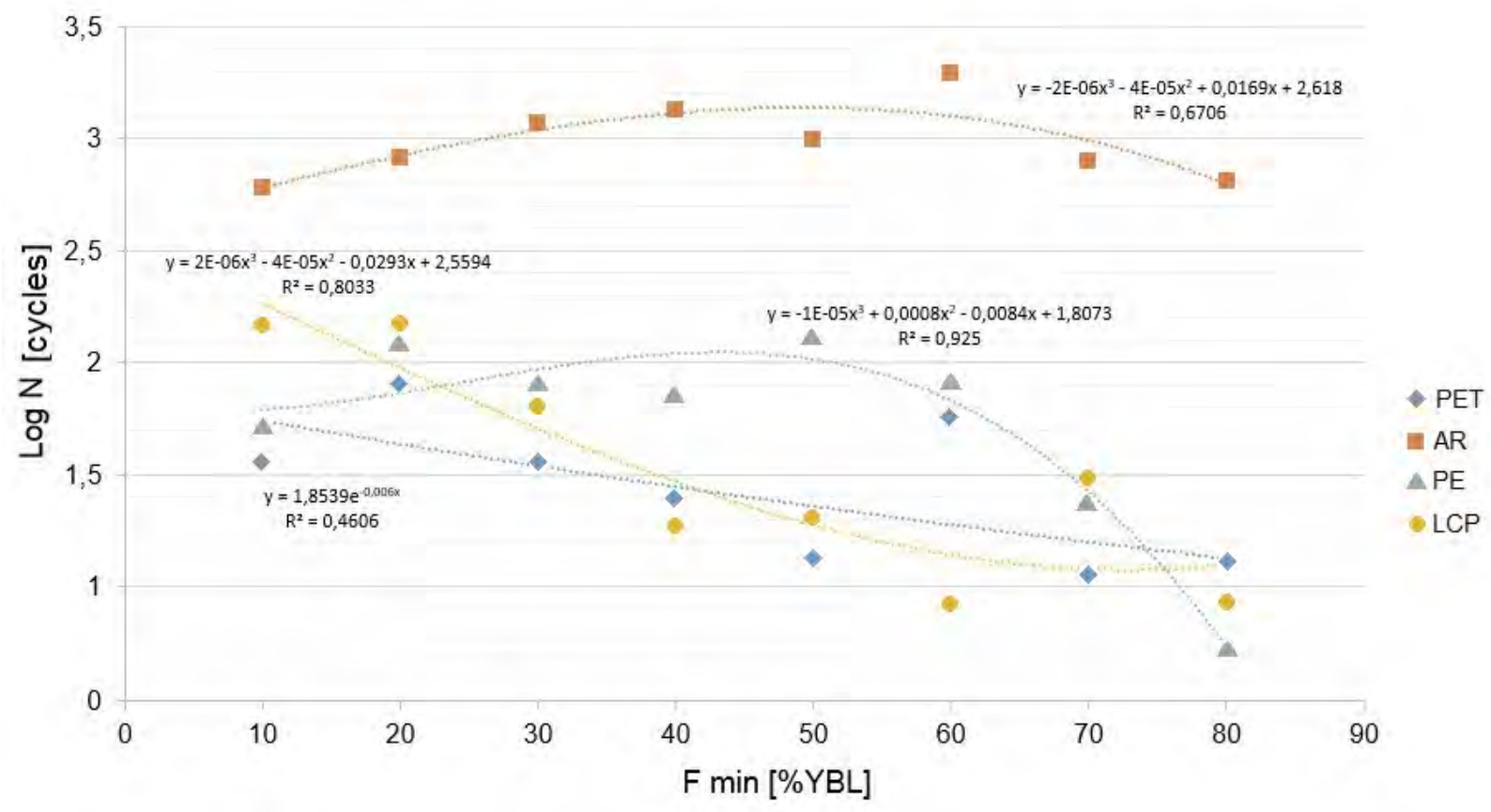

Figure 11. Comparative fatigue diagram.

\begin{tabular}{lrrrrrrrrr}
\hline Trough Load [\% YBL] & $\mathbf{1 0}$ & $\mathbf{2 0}$ & $\mathbf{3 0}$ & $\mathbf{4 0}$ & $\mathbf{5 0}$ & $\mathbf{6 0}$ & $\mathbf{7 0}$ & $\mathbf{8 0}$ & Total Avg. \\
\hline PET & 36 & 79 & 36 & 26 & 13 & 57 & 11 & 13 & $\mathbf{3 4}$ \\
\hline AR & 600 & 834 & 1167 & 1352 & 993 & 1947 & 776 & 660 & $\mathbf{1 0 4 1}$ \\
\hline PE & 51 & 120 & 80 & 71 & 131 & 80 & 24 & 5 & $\mathbf{7 0}$ \\
\hline LCP & 143 & 146 & 62 & 18 & 20 & 8 & 30 & 9 & $\mathbf{5 5}$ \\
\hline
\end{tabular}

TABLE 3. Average number of cycles to failure by fatigue.

fibres, although, as numerical simulations indicated, it involves extensive testing routines. Also, despite of the tests being carried out exclusively under extreme loading conditions, it is possible to observe an endurance tendency particular to each studied material when submitted to cyclic stress.

The fibres PET and LCP present a similar tendency having their cyclic endurance decreased as the amplitude decreases, while AR and HMPE have both an optimal endurance amplitude of about $20 \%$ YBL. Despite this difference, all four materials have their average fatigue resistance decreased at low loading amplitudes.

The results obtained for PET must be taken into account as a representation of a real Polyester rope behaviour, once experimental tests with yarns are known to provide results faithful and proportional to what an actual rope would produce [19].

\section{Future Work}

Due to time and cost feasibilities, the eight cyclic loading tracks studied had as fixed peak load $90 \%$ YBL for each fibre. Therefore, as the behaviour of the materials studied are still unknown for other loading conditions, it is suggested that the same study is carried out with other fixed peak loads in order to analyse if the behaviour of all fibres remain the same on both occasions: when compared with each other , and when analyzed individually.

Also, the performed analysis aimed at one specific fibre from different manufacturers could verify whether the mechanical behaviour is inherent to the material only, or if the manufacturing process plays a significant role on the fatigue resistance of the polymer.

The influence of the specimen scale might as well be studied carrying out the same tests under identical proportional loading conditions and with the same materials. Always supported by proper standard testing regulations for the scale chosen (i.e. fibre, strand, sub cable), the discovery of a constant or function that defines the change in fatigue resistance through the number of yarns associated on it, would be a great gain in applying the research to industry needs, once mathematical extrapolations could be constituted to predict, in the best case scenario, the behaviour of an actual gross rope.

\section{LIST OF SYMBOLS}

PET Polyester

AR Aramid 


\author{
PE Polyethylene \\ LCP Liquid Crystal Polymer \\ MBL Maximum Breaking Load [N] \\ YBL Yarn Breaking Load [N] \\ RH Relative Humidity \\ CR Creep Resistance [h] \\ LD Linear Density [tex] \\ LT Linear Tenacity [N/tex] \\ CRL Constant Rate of Loading \\ $\mathrm{N}$ Number of Cycles \\ $R^{2}$ Correlation Coefficient
}

\section{ACKNOWLEDGEMENTS}

This investigation was realized with the contribution of the Brazilian companies Petrobras and ANP - Petroleum National Agency.

\section{REFERENCES}

[1] Zivkovic, I., Pavlovic, A., Fragassa, C.: Improvements in wood thermoplastic composite materials properties by physical and chemical treatments. In: International Journal of Quality Research (Editors: Z. Krivokapic and S. Arsovski). 2016, 10, p. 205-218.

[2] Dawson, D.: Focus on Design: Solar-powered composite car designed to win. In: High-Performance Composites, September 2007.

[3] Fotouhi, M., Saghafi, H., Brugo, T., Minak, G., Fragassa, C., Zucchelli, A., Ahmadi, M.: Effect of PVDF nanofibers on the fracture behavior of composite laminates for high-speed woodworking machines. In: Proceedings of the Institution of Mechanical Engineers, Part C: Journal of Mechanical Engineering Science, 2016, DOI: $10.1177 / 0954406216650711$.

[4] Bosman, R. L.: On the origin of heat build-up in polyester ropes. Fort Lauderdale: Oceans Conference, 1996.

[5] Husak, G. S., Chimisso, F. E. G.: Construction of a Device to Test Creep Behavior of Synthetic Multifilaments, Submerged in Cold Water, Used in Offshore Mooring Systems, and Results. Brasov: 11th Youth Symposium on Experimental Solid Mechanics, 2012.

[6] Stumpf, F. T., Guilherme, C. E. M., Chimisso, F. E. G.: Preliminary Assessment of the Change in the Mechanical Behavior of Synthetic Yarns Submitted to Consecutive Stiffness Tests. In: Acta Polytechnica CTU Proceedings, 2016, 3, p. 75.
[7] M. Zoroufi.: Significance of Fatigue Testing Parameters in Plastics versus Metals. Jacksonville: 13th International ASTM/ESIS Symposium on Fatigue and Fracture Mechanics, 2013.

[8] Fragassa, C.: Investigations into the degradation of PTFE surface properties by accelerated aging tests. In: Tribology in Industry (Editor: Slobodan Mitrovic). 2016, 38, No. 2, p. 241-248.

[9] Giorgini, L., Fragassa, C., Zattini, G., Pavlovic, A.: Acid aging effects on surfaces of PTFE gaskets investigated by Fourier Transform Infrared Spectroscopy. In: Tribology in Industry (Editor: Slobodan Mitrovic). 2016, 38, No. 3, p. 286-296.

[10] Poodts, E., Minak, G., Zucchelli, A.: Impact of sea-water on the quasi static and fatigue flexural properties of GFRP. In: Composite Structures (Editor: A. J. M. Ferreira). Elsevier, 2013, 97, p. 222-230.

[11] McKenna, H. A., Hearle, J. W. S., OHear, N.: Handbook of Fibre Rope Technology. Woodhead Publishing Ltd and CRC Press LLC, 2004.

[12] Pfarrius, J. D. et al.: Theoretical and Experimental Modeling of a Socket Sandwich for Use in Tension Tests of Synthetic Ropes. Vrnjacka Banja: 6th Youth Symposium on Experimental Solid Mechanics, 2007.

[13] American Society for Testing and Materials, ASTM D885: Standard Test Methods for Tire Cords, Tire Cord Fabrics, and Industrial Filament Yarns Made from Manufactured Organic-Base Fibers. West Conshohocken, 1998.

[14] Associacao Brasileira de Normas Tecnicas, NBR 13214: Determinacao de titulo de fios. Rio de Janeiro, 1994.

[15] International Standardization Organization, ISO 2060: Textiles: Yarns from packages, Determination of linear density. Geneva, 1994.

[16] International Standardization Organization, ISO 139: Textiles: Standard atmospheres for conditioning and testing. Geneva, 2005.

[17] Saghafi, H., Brugo, T. M., Zucchelli, A., Fragassa, C., Minak, G.: Comparison of the Effect of Preload and Curvature of Composite Laminate Under Impact Loading. In: FME Transactions (Editor: Bosko Rasuo). 2016, 44, p. 353-357.

[18] Det Norsk Veritas, DNV: Yarns for Offshore Mooring Fibre Ropes. Hovik, 2010.

[19] Rossi, R. R.: Cabos de Poliester para Ancoragem de Plataformas de Petroleo em Aguas Ultraprofundas. Thesis of M.Sc. in Oceanic Engineering. Universidade Federal do Rio de Janeiro, Rio de Janeiro, 2002. 